\title{
Physiological, Nutritional and Performance Profiles of Brazilian Jiu-Jitsu Athletes
}

\author{
by \\ Leonardo V Andreato ${ }^{1,2}$, Jonatas FS Santos ${ }^{1}$, João VDC Esteves ${ }^{3}$, \\ Valeria LG Panissa ${ }^{1}$, Ursula F Julio ${ }^{1}$, Emerson Franchini ${ }^{1}$
}

\begin{abstract}
This study analysed the physiological, nutritional and performance profiles of athletes practicing Brazilian jiujitsu. To this end, 15 athletes that practiced Brazilian jiu-jitsu (aged: $28 \pm 5$ years; 8 brown belts and 7 black belts; training experience: $11 \pm 4$ years) underwent anthropometric measurements (body composition and somatotype), dietary evaluation ( $24 \mathrm{~h}$ recall) and physical fitness tests (movement time, dynamometer handgrip, kimono grip strength, vertical jump and sit-and-reach tests). The athletes had $12.7 \pm 4.8 \%$ of body fat, $59.2 \pm 5.0 \%$ of muscle mass and their somatotype was dominated by the mesomorphic component $(5.3 \pm 2.0)$, followed by endomorphic (3.7 \pm 1.5$)$ and ectomorphic $(1.4 \pm 0.9)$ components. Nutritional assessment suggested a diet consisting of $54 \pm 7 \%$ of carbohydrates, $19 \pm 4 \%$ of protein and $27 \pm 6 \%$ of lipids. Movement time on the handgrip tests was $0.42 \pm 0.05 \mathrm{~s}$, for handgrip strength, $53 \pm 7 \mathrm{kgf}$ was found for the dominant hand and $50 \pm 9 \mathrm{kgf}$ for the non-dominant hand. For the countermovement jump, the jiu-jitsu athletes reached $41 \pm 5 \mathrm{~cm}$. Athletes remained $30 \pm 14 \mathrm{~s}$ in the maximum static suspension test gripping a kimono, and reached $27 \pm 8 \mathrm{~cm}$ in the sit-and-reach test. Overall the sample presented average levels of body fat, elevated muscle mass and a predominantly mesomorphic somatotype. Diet was generally poor, with low carbohydrate intake, high protein intake and adequate lipid intake. Maximum isometric handgrip strength was consistent with observations of other athletes in this sport discipline. However, the performance in the maximum static suspension test gripping a kimono was lower than in other Brazilian jiu-jitsu athletes. Movement time was comparable and lower body muscle power was worse compared to athletes in similar sports. Additionally, flexibility was rated as poor.
\end{abstract}

Key words: combat sport, sports performance, physical fitness evaluation, anthropometrics.

\section{Introduction}

Brazilian jiu-jitsu is a grappling combat sport in which athletes aim to immobilize and finish the fight from the joint-locks (wrist, elbow, knee and ankle locks), strangle and pressure techniques. The first Brazilian Jiu-Jitsu World Championship was held in 1996, and since then, the number of practitioners and athletes has considerably increased (IFBJJ, 2014). However, little is known about the physiological and nutritional aspects of Brazilian jiu-jitsu compared to other grappling combat sports such as judo (first World Championship in 1951 and an Olympic demonstration sport in 1964) (Brousse and Matsumoto, 1999) and wrestling (first GrecoRoman World Championship in 1904 and an Olympic sport since 1896) (Ray, 2007). Over the last two decades, the sport has increased in popularity, especially due to the success of

\footnotetext{
1 - Department of Sport, School of Physical Education and Sport, University of São Paulo, São Paulo, Brazil.

2 - Santa Catarina State University, Sciences Center of Health and Sport, Florianópolis-SC, Brazil.

3 - Institute of Biomedical Sciences, Department of Physiology and Biophisics, University of São Paulo, Brazil.
} 
Brazilian jiu-jitsu athletes in mixed martial arts events.

It is thus becoming more important to understand the characteristics of the sport and the athletes. The increase in practitioners has been mirrored by a growing number of studies focused on Brazilian jiu-jitsu. Most of them have aimed to describe morphological characteristics of athletes (Andreato et al., 2012a), their functional (Silva et al., 2014; Vidal-Andreato et al., 2011) or physiological responses to exercise (Andreato et al., 2012b; Coswig et al., 2013; Moreira et al., 2012; Silva et al., 2013) and competition (Andreato et al., 2013, 2014; Moreira et al., 2012). There have also been studies comparing the profiles of Brazilian jiu-jitsu athletes (Silva et al., 2012, 2014).

In competition athletes are categorised by gender, age, body mass and the grade in the sport. Duration of a fight between adult males varies from 6 (blue belts) to 10 min (black belts) (IFBJJ, 2014). Intermittency is the main characteristic of this type of combat. In regional Brazilian jiu-jitsu matches approximately $120 \mathrm{~s}$ of fighting are interspersed with $20 \mathrm{~s}$ pauses (Andreato et al., 2013). Extensive research indicates that Brazilian jiu-jitsu athletes tend to have low body fat, a predominantly mesomorphic somatotype (Andreato et al., 2012a; Del Vecchio et al., 2007) and comparatively low maximal strength on tests of the isometric handgrip, which is relevant to performing at maximum strength (Andreato et al., 2013; Vidal-Andreato et al., 2011). Additionally, divergent results have been found concerning flexibility ranging from average to above average rating (Del Vecchio et al., 2007; Vidal-Andreato et al., 2011).

However, there are gaps in the existing body of evidence and understanding of the sport is incomplete; for example there is no published evidence on the dietary habits of Brazilian jiu-jitsu athletes. This information is important considering that for competition athletes are divided into categories related to body mass and a large proportion use weight reduction techniques before competitions (Brito et al., 2012). Additionally, researchers have mostly analyzed just a few or isolated performance components. Thus, this study aimed to conduct a comprehensive analysis of the physiological, nutritional and performance profiles of athletes that practiced Brazilian jiu-jitsu. The hypothesis of the present study was that nutritional intake and performance in physical tests were significantly related.

\section{Material and Methods}

\section{Participants}

The study included 15 adult male Brazilian jiu-jitsu athletes (age: $28 \pm 5$ years), with $11 \pm 4$ years of training experience ( 8 brown belts and 7 black belts). This study was conducted 12 weeks after the main competitions. The athletes were at the beginning of the transition phase, but were not detrained.

The inclusion criteria were as follows: rank of the brown belt or higher, to ensure a similar experience between participants; training frequency of at least three times a week with respect to training specific to Brazilian jiu-jitsu, which is generally in the form of $1 \mathrm{~h} 30 \mathrm{~min}$ sessions and a history of training for at least three consecutive months.

Athletes were excluded from the study if they had injuries, were considerably overweight $(>100 \mathrm{~kg}$ ), were attempting to reduce body mass or were using illegal (e.g. anabolic steroids) or legal drugs (e.g. antibiotics and anti-inflammatory medications). Athletes who used dietary supplements were advised to keep their usage constant during the study. The subjects were also instructed to refrain from all forms of physical activity for $24 \mathrm{~h}$ before data collection. After being briefly informed about the procedures and purposes of the study, they provided written informed consent for participation. The study was approved by the Ethics Research Committee of the School of Physical Education and Sport of the University of São Paulo.

\section{Procedures}

Body mass and height.

Body mass and height were measured according to a previously described protocol (Lohman et al., 1988) using a scale that was accurate to $0.1 \mathrm{~kg}$ and a height stadiometer that was accurate to $0.1 \mathrm{~cm}$. Measurements of body mass and height were used to determine the body mass index (BMI) calculated as the ratio of body mass to height ${ }^{2}\left(\mathrm{~kg} / \mathrm{m}^{2}\right)$.

Perimeters.

The perimeters of the forearm, thigh and leg were obtained according to the Lohman et al.'s (1988) protocol. The perimeter of the arm when 
contracted was measured as the point of greatest volume at the end of a maximal voluntary contraction of the biceps. All measurements were taken using a tape measure that was accurate to $0.1 \mathrm{~cm}$. Bone diameters of the humeral and femoral bicondyles were obtained using a caliper with precision of $0.1 \mathrm{~cm}$, following the Lohman et al.'s (1988) procedure.

Skinfolds.

Skinfold thickness measurements (chest, mid-axillary, triceps, subscapular, abdominal, suprailiac and medial thigh) were taken in triplicate using a Harpender plicometer with a rotation system (the average value was used) according to the Lohman et al.'s (1998) protocol. Body density.

Body density (BD) was estimated from skinfold thickness using the Jackson and Pollock's (1978) formula:

$\mathrm{BD}=1.11200000-0.00043499\left(\sum 7 \mathrm{EDC}\right)+$ 0.00000055 ( $\left.\sum 7 \mathrm{EDC}\right) 2-0.00028826$ (Age)

where $\Sigma 7 \mathrm{EDC}$ is the sum of the thickness of seven skinfolds (chest, mid-axillary, triceps, subscapular, abdominal, suprailiac and thigh).

Body fat.

The Siri's (1961) equation was used to estimate body fat:

$\mathrm{BF} \%=[(4.95 / \mathrm{BD})-4.50] \times 100$

where $\mathrm{BF} \%$ is the percentage of body fat.

Muscle mass.

Muscle mass (MM) was estimated using the Martin et al.'s (1990) equation:

$\mathrm{MM}(\mathrm{g})=\mathrm{H}\left(0.0553 \cdot \mathrm{CT}^{2}+0.0987 \cdot \mathrm{PC}^{2}+0.0331 \cdot\right.$ $\left.\mathrm{PP}^{2}\right)-2445$

where $\mathrm{H}$ is height, $\mathrm{CT}$ is thigh circumference corrected for skinfold thickness of the thigh, PF is the forearm perimeter and PC is calf circumference corrected for skinfold thickness in the medial leg area; all measurements are in inches. The perimeters of the thigh and calf minus the values found by the value of $\pi$ multiplied by skinfold thickness were fixed.

Somatotype.

The determination of the athletes' somatotype was based on the ten following measurements according to the protocol described by Carter and Heath (1990): body mass, body height, skinfold measurement (triceps, subscapular, supraspinal and medial calf), girth (flexed arm, and calf) and bone diameters (humeral and femoral bicondyles).

\section{Nutritional Status}

Food intake. Athletes completed a $24 \mathrm{~h}$ food diary, during two non-consecutive days, from which intake of macronutrients was estimated according to the procedure described by Degoutte et al. (2003). Calculations were made using Nutrilife $8.1^{\circledR}$ software. Daily intake records were compared with recommended nutritional intake for athletic men (Martin, 2011).

\section{Physical Performance}

Battery of physical tests.

To assess reproducibility of physical measurements, the athletes performed the test battery twice, with a $5 \mathrm{~min}$ interval in between. The reliability for each test was calculated using the intraclass correlation coefficients (ICC), standard error of measurement (SEM) and limits of agreement (LOA, mean and the 95\% confidence interval). The results indicated elevated reliability for the tests used, as follows: movement time $\mathrm{ICC}=0.82, \mathrm{SEM}=0.03 \mathrm{~s}, \mathrm{LOA}=0.025 \mathrm{~s}(95 \%$ confidence interval $=-0.003$ to $0.054 \mathrm{~s}$ ); dominant handgrip - ICC $=0.91, \mathrm{SEM}=3.8 \mathrm{kgf}, \mathrm{LOA}=0.5$ $\mathrm{kgf}(95 \%$ confidence interval $=-2.0$ to $3.0 \mathrm{kgf})$; non-dominant handgrip - ICC $=0.91, \mathrm{SEM}=4.6$ $\mathrm{kgf}, \mathrm{LOA}=1.0 \mathrm{kgf}(95 \%$ confidence interval $=-1.8$ to $3.8 \mathrm{kgf}$ ); vertical jump - ICC $=0.94, \mathrm{SEM}=2.0$ $\mathrm{cm}, \mathrm{LOA}=-0.4 \mathrm{~cm}(95 \%$ confidence interval $=-1.5$ to $0.7 \mathrm{~cm}$ ); strength-endurance - ICC $=0.93, \mathrm{SEM}=$ $7.0 \mathrm{~s}, \mathrm{LOA}=4.0 \mathrm{~s}$ (95\% confidence interval $=0.3$ to $7.8 \mathrm{~s}$ ); flexibility $-\mathrm{ICC}=0.98, \mathrm{SEM}=2.1 \mathrm{~cm}, \mathrm{LOA}=$ $-0.6 \mathrm{~cm}(95 \%$ confidence interval $=-1.6$ to $0.4 \mathrm{~cm})$. Movement time.

The movement time was determined using the interval between the acoustic signal and the mechanical response (Kraemer et al., 2001). The athlete was instructed to remain upright and stable over a jump platform (Hidrofit ${ }^{\circledR}$, Belo Horizonte, Brazil) controlled by MultiSprint ${ }^{\circledR}$ software (Hidrofit ${ }^{\circledR}$, Belo Horizonte, Brazil). After a sound stimulus, the athlete reacted as quickly as possible performing a jump. Three attempts were made, with the best value obtained recorded. A 1 min interval between attempts (Brown and Weir, 2003) was allowed.

Maximal isometric handgrip strength.

The test was performed with a Jamar ${ }^{\circledR}$ dynamometer model J00105 (Lafayette Instrument ${ }^{\circledR}$, Lafayette, USA), which was adjusted according to the size of the hand of each athlete. The results are presented in kilogram-force (kgf). 
Athletes performed the test standing with their arms at the sides. In this position the athlete was asked to grip as hard as possible for approximately $3 \mathrm{~s}$. The wrist, elbow and shoulder had to be immobile during the test (Johnson and Nelson, 1979). Three non-sequential trials were performed with each hand, and the maximum value was recorded. There was a 1 min rest interval between attempts (Brown and Weir, 2003).

Maximum static suspension test gripping a kimono.

The athlete performed his grip in the kimono, which was previously positioned on the bar, with maximum flexion of the elbows, holding that position as long as possible. This procedure was described in a previous study (Franchini et al., 2011). The time was manually obtained with precision of seconds. Only one attempt was allowed. We used solely the isometric version of this test considering that Silva et al. (2014) reported that the isometric kimono grip pull-up test was able to discriminate isometric strength endurance between four different levels of Brazilian jiu-jitsu groups, while the dynamic kimono grip pull-up test only discriminated strength endurance with larger differences concerning practice/competitive levels.

Countermovement jump.

The jump test was performed using the countermovement technique. The results are presented in centimeters $(\mathrm{cm})$. This procedure was performed on a contact mat (Hidrofit ${ }^{\circledR}$, Belo
Horizonte, Brazil) controlled by MultiSprint ${ }^{\circledR}$ software (Hidrofit ${ }^{\circledR}$, Belo Horizonte, Brazil). The athletes were standing, hands free, and jumped as high as possible. During the aerial phase, the athletes kept their knees extended (Cronin and Hansen, 2005). Three attempts were made, with the highest obtained value recorded for further analysis. There was a $1 \mathrm{~min}$ rest interval between attempts (Brown and Weir, 2003).

Flexibility.

Flexibility was measured using a sit-andreach test. The results are presented in centimeters $(\mathrm{cm})$. The participant sat with knees straight and feet flat on the bench, then inclined his or her trunk forwards as far as possible (Johnson and Nelson, 1979). Three attempts were performed and the maximum inclination was recorded. There was a $1 \mathrm{~min}$ interval between attempts (Brown and Weir, 2003).

Statistical Analysis

Data are presented as mean, standard deviation, $95 \%$ the confidence interval $(95 \% \mathrm{CI})$, range (minimum and maximum) and the percentage. Reliability for each test was calculated using the intraclass correlation coefficients (ICC), standard error of measurement (SEM) and limits of agreement (LOA). Normality was assessed with the use of the Shapiro-Wilk test and Pearson's or Spearman's correlations coefficients were calculated in order to examine the relationships between variables. The level of significance was set at $5 \%$.

\begin{tabular}{|c|c|c|c|c|}
\hline \multirow{2}{*}{\multicolumn{5}{|c|}{ Anthropometric characteristics of Brazilian jiu-jitsu athletes $(n=15)$}} \\
\hline & & & & \\
\hline Variable & Mean & SD & $95 \% \mathrm{CI}$ & Range \\
\hline Body mass (kg) & 80.3 & 7.8 & $75.8-84.8$ & $68.0-98.3$ \\
\hline Body height $(\mathrm{cm})$ & 177.5 & 6.4 & $173.8-181.2$ & $163.5-188.0$ \\
\hline $\mathrm{BMI}\left(\mathrm{kg} / \mathrm{m}^{2}\right)$ & 25.6 & 2.9 & $23.9-27.2$ & $19.4-31.7$ \\
\hline Body fat (\%) & 12.7 & 4.8 & $9.9-15.5$ & $7.6-25.1$ \\
\hline Body fat $(\mathrm{kg})$ & 10.5 & 5.2 & $7.5-13.4$ & $5.8-24.7$ \\
\hline LBM (kg) & 69.8 & 4.3 & $67.4-72.3$ & $62.0-75.6$ \\
\hline $\mathrm{MM}(\mathrm{kg})$ & 47.5 & 5.8 & $44.1-50.9$ & $40.4-60.9$ \\
\hline MM (\%) & 59.2 & 5.0 & $56.3-60.1$ & $54.7-73.3$ \\
\hline \multicolumn{5}{|l|}{ Somatotype } \\
\hline Ectomorphy & 1.4 & 0.9 & $0.9-2.0$ & $0.0-3.6$ \\
\hline Mesomorphy & 5.3 & 2.0 & $4.1-6.4$ & $1.3-9.9$ \\
\hline Endomorphy & 3.7 & 1.5 & $2.9-4.6$ & $2.4-8.0$ \\
\hline \multicolumn{5}{|c|}{$\begin{array}{c}\text { BMI = Body mass index; } L B M=\text { lean body mass; } M M=\text { muscle mass. } \\
\text { SD: standard deviation, } 95 \% \text { CI: } 95 \% \text { confidence interval. }\end{array}$} \\
\hline
\end{tabular}


Table 2

Food intake of Brazilian jiu-jitsu athletes ( $n=15)$

\begin{tabular}{lccccc}
\hline \multicolumn{1}{c}{ Variable } & Mean & SD & 95\% CI & Range & $\begin{array}{c}\text { Recommended } \\
\text { Dietary }\end{array}$ \\
\hline Energy intake (kJ) & 15.492 & 5100 & $12.668-18.316$ & $7.917-29.339$ & - \\
Energy intake (kJ/kg/day) & 194 & 66 & $159-232$ & $95-361$ & - \\
Carbohydrate (g) & 499 & 181 & $399-600$ & $208-990$ & - \\
Carbohydrate (g/kg/day) & 6.3 & 2.3 & $5.0-7.6$ & $2.5-12.2$ & - \\
Carbohydrate (\%) & 54 & 7 & $50-58$ & $41-64$ & - \\
Protein (g) & 168 & 78 & $125-212$ & $18-378$ & - \\
Protein (g/kg/day) & 2.2 & 1.0 & $1.6-2.7$ & $0.2-4.7$ & 15 \\
Protein (\%) & 19 & 4 & $17-21$ & $15-30$ & - \\
Fat (g) & 109 & 45 & $84-134$ & $47-194$ & - \\
Fat (g/kg/day) & 1.4 & 0.6 & $1.1-1.7$ & $0.5-2.4$ & $18-43$ \\
Fat (\%) & 27 & 6 & $23-30$ & $11-66$ & $1 / 3$ of total fat \\
Saturated fat (g) & 35 & 16 & $26-44$ & $28-52$ & $1 / 3$ of total fat \\
Monounsaturated fat (g) & 29 & 14 & $21-37$ & $20-56$ & $1 / 3$ of total fat \\
Polyunsaturated fat (g) & 25 & 14 & $17-39$ & & - \\
\hline
\end{tabular}

SD: standard deviation, 95\% CI: 95\% confidence interval.

Table 3

Physical performance of Brazilian jiu-jitsu athletes ( $n=15)$.

\begin{tabular}{lcccc}
\hline \multicolumn{1}{c}{ Variable } & Mean & SD & $\mathbf{9 5 \% ~ C I ~}$ & Range \\
\hline Movement time (s) a & 0.42 & 0.05 & $0.39-0.45$ & $0.33-0.53$ \\
D-HG (kgf) & 53 & 7 & $49-57$ & $42-66$ \\
ND-HG (kgf) & 50 & 9 & $45-54$ & $36-62$ \\
CMJ (cm) & 41 & 5 & $38-44$ & $35-51$ \\
Grip endurance (s) & 30 & 14 & $22-38$ & $7-60$ \\
Sit and reach (cm) & 27 & 8 & $23-32$ & $9-40$ \\
\hline
\end{tabular}

$a: n=13$. D-HG: dominant handgrip, ND-HG: non-dominant handgrip, CMJ: countermovement jump. SD: standard deviation, 95\% CI: 95\% confidence interval.

\section{Results}

Table 1 shows anthropometric characteristics of the Brazilian jiu-jitsu athletes. The athletes showed a normal fat percentage, elevated muscle development and the mesomorphic somatotype component as predominant.

Table 2 shows the dietary intake of Brazilian jiu-jitsu athletes. There was wide variation in energy consumption (7.917-29.339 kJ); intake of carbohydrates was low, whereas protein intake was high.

Table 3 presents variables related to the physical performance of the athletes.

Significant correlations were found between the following variables: isometric handgrip strength and body mass $(\mathrm{r}=0.54 ; p=0.046)$, absolute lean mass ( $\mathrm{r}=0.60 ; p=0.022)$ and absolute muscle mass ( $\mathrm{r}=0.56 ; p=0.036)$; suspension time in the maximum static 
suspension gripping a kimono test and absolute body fat $(\mathrm{r}=-0.55 ; p=0.040)$, body fat percentage $(\mathrm{r}=-0.59 ; p=0.027)$, and endomorphy $(\mathrm{r}=-0.61 ; p$ $=0.022)$. No significant correlation was found between nutritional aspects and performance in the physical tests.

\section{Discussion}

The aim of this study was to analyse the physiological and nutritional profiles along with the physical performance of Brazilian jiu-jitsu athletes. The results indicate that Brazilian jiujitsu athletes had a low percentage of body fat (NIH, 1998), elevated muscle mass and the predominance of the somatotype mesomorphic component (Carter and Heath, 1990). It was also noted that the athletes had a poor diet, with low carbohydrate and high protein intake (Martin, 2001). Maximal isometric handgrip strength was similar to that seen in other samples of Brazilian jiu-jitsu athletes (Andreato et al., 2011, 2013; Silva et al., 2014). However, the isometric strengthendurance performance in the maximum static suspension kimono grip test was lower than previously reported in other Brazilian jiu-jitsu athletes (Silva et al., 2012, 2014). Movement time was comparable and the lower-body muscle power was worse than that of athletes of similar modalities (Franchini et al., 2011). Flexibility was, however, rated as poor (ACSM, 2000; Heyward and Gibson, 2014).

This study showed that Brazilian jiu-jitsu athletes presented a low body fat percentage and prevalence of the mesomorphic somatotype component. Body fat content in our sample was within the recommended range which is 5 to $18 \%$ for men (NIH, 1998). Our findings are similar to those of previous studies of Brazilian jiu-jitsu athletes, which reported body fat content between 9 and 11\% (Andreato et al., 2012a; Del Vecchio et al., 2007). At these levels it is still possible for the athletes to have good muscle development. The athletes in this study had 59\% lean muscle mass and prevalence of the mesomorphic component, followed by endomorph and ectomorph somatotype components. A previous study (Andreato et al., 2012a) described a lean mass percentage $(61 \%)$ in Brazilian jiu-jitsu athletes as close to that found in the present study. Indeed, the superiority of the mesomorphic component over the other components of the somatotype has been featured among Brazilian jiu-jitsu athletes (Del Vecchio et al., 2007).

The mean BMI of Brazilian jiu-jitsu athletes obtained in this study was similar to that reported in a previous study (Andreato et al., 2012a). Both values are in the range considered to represent overweight (WHO, 1995); however, the BMI is based solely on total body mass and height, and disregards other factors. Taking into account other variables which discriminate between the different body components (Table 1), we suggest that the BMI values obtained in this study reflect a notable development of fat-free mass.

This knowledge about the morphological characteristics of Brazilian jiu-jitsu athletes is important, as the regulation of body mass is a major concern in this sports discipline. This concern is justified since competitors are categorised by weight; there are nine categories of weight (measured in a kimono): Rooster: $<54 \mathrm{~kg}$; Light Feather: $<64$ kg; Feather: $<70$ kg; Light: $<76$ $\mathrm{kg}$; Middle: $<82.3 \mathrm{~kg}$; Medium Heavy: $<88.3 \mathrm{~kg}$; Heavy: < 94 kg; Super Heavy: < 100.5 kg; Ultra Heavy: $>100.5 \mathrm{~kg}$, in addition to the open division (no weight division) (IFBJJ, 2014). It is therefore common for athletes to reduce body mass before a competition. Besides, a recent study showed that $50 \%$ of athletes at the national and international level, and $62.5 \%$ of athletes at the regional level reduced body mass to compete (Brito et al., 2012). Preparation for competition thus involves regulating body composition and knowledge about nutritional intake is essential to this process.

In addition, the control of the body composition is important considering that previous studies have reported a negative relationship between body fat and performance during a Cooper test and technical actions during a judo match (Franchini et al., 2005, 2007). However, this relationship (body composition and performance) has not been previously reported in Brazilian jiu-jitsu. Despite this, previous studies did not find differences in body fat between beginners $(n=7,8.7 \pm 3.8 \%)$ and experienced $(n=7,9.1 \pm 3.0 \%)$ athletes (Coswig et al., 2011) or elite ( $\mathrm{n}=7,9.0 \pm 2.6 \%)$ and non-elite ( $\mathrm{n}$ $=7,9.1 \pm 3.1 \%$ ) athletes (Andreato et al., 2010).

Another important performance factor is the diet of the athletes. It is well known that unbalanced diets, especially those with a low 
carbohydrate content, can impair performance, since these diets reduce glycogen stores (Degoutte et al., 2003). The recommended intake is approximately $60 \%$ carbohydrates, $15 \%$ protein and less than $30 \%$ fat (Martin, 2001). In this study we found that Brazilian jiu-jitsu athletes' carbohydrate intake was below the recommended level for male athletes $(54 \pm 7 \%)$, protein intake was above the recommended level $(19 \pm 4 \%)$ and fat intake was in line with recommendations $(27 \pm$ $6 \%)$.

We also observed that the wu-shu athletes tended to have unbalanced diets that were especially low in carbohydrates (Artioli et al., 2009). This aspect deserves attention as, based on blood lactate concentration $(\sim 10 \mathrm{mmol} / \mathrm{L})$ after the combat, it is suggested that Brazilian jiu-jitsu exerts moderate activation of the glycolytic pathway (Andreato et al., 2012b, 2013), which can decrease during successive combats (Andreato et al., 2015a). It has also been well documented that low carbohydrate intake reduces muscle glycogen stores, which has a negative impact on performance at high intensity and/or over the long term (Correia-Oliveira et al., 2013). We also found that protein intake in our sample was above the recommended daily level (Table 3) (Lemon, 2000). However, no significant correlation was found between energy intake and physical performance in the tests used in the present study. One limitation of our study is that the athletes were not preparing for a specific competition and this may have affected their diet control, i.e., a less controlled and high-quality diet should have been consumed in this period. Another important limitation was the use of only two non-consecutive days to assess the athletes' diet.

It is important to describe and understand physical performance variables as well as the anthropometric and dietary characteristics of athletes. Reaction time is a crucial factor in situations that require rapid decisions, such as blocking an attack or to apply a counter attack in Brazilian jiu-jitsu. The athlete should be able to react quickly with an attack or counter-attack. It has been reported that in fights between Brazilian jiu-jitsu athletes, mean reaction time to an opponent's move was $0.42 \pm 0.05 \mathrm{~s}$ (Mori et al., 2002). One would expect more experienced athletes to react more quickly; however, comparisons between groups differing in training status have provided divergent results (Chung and $\mathrm{Ng}, 2012$ ), especially when the task was not adopted to a specific mode. This value was similar to that reported in a study of wrestlers (Kraemer et al., 2001). We found only one study that had evaluated this performance variable in Brazilian jiu-jitsu athletes. Andrade et al. (2014) reported mean reaction time of $0.24 \pm 0.17 \mathrm{~s}$, however, they considered movement time (time to complete a response to the stimulus) rather than response time (time to initiate a response to the stimulus).

Handgrip strength and handgrip strength endurance are important abilities for the athletes perform the combat gripping the opponent's kimono (e.g., gripping dispute, controlling the opponent, applying techniques) (Vidal-Andreato et al., 2011). In addition, expert Brazilian jiu-jitsu athletes (with great experience, training status, and a competition level) presented higher values of isometric handgrip strength than a group of novice Brazilian jiu-jitsu fighters (Diaz-Lara et al., 2014). Moreover, previous studies showed that athletes reported a higher perception of fatigue in the forearm region after combats (Andreato et al., 2013, 2015b; Franchini et al., 2005b).

For handgrip strength, previous studies reported values between 40 and $52 \mathrm{kgf}$ in Brazilian jiu-jitsu athletes (Andreato et al., 2013; Silva et al., 2014; Vidal-Andreato et al., 2011). Handgrip strength in our sample was consistent with previous reports (Andreato et al., 2013; Silva et al., 2014; Vidal-Andreato et al., 2011). We also found that handgrip strength in the dominant and non-dominant hands was similar; this is the first study to have investigated this aspect of functional symmetry in Brazilian jiu-jitsu athletes. Additionally, body mass, muscle mass and lean body mass were positively correlated to handgrip strength in the non-dominant hand, suggesting that maximal strength is related to muscle development.

The strength-endurance performance in the maximum static suspension test gripping a kimono, as Franchini et al. (2011) described, has been already studied in Brazilian jiu-jitsu athletes (Silva et al., 2012, 2014). Superior results were found in previous studies (Silva et al., 2012, 2014). The results were higher when experienced athletes were compared with the beginners $(45 \pm$ 36 vs. $10 \pm 10 \mathrm{~s}, \mathrm{p}=0.04)$ at the time of suspension 
(Silva et al., 2014). The suspension time in the strength-endurance isometric test also discriminated between elite and non-elite athletes (56 \pm 11 vs. $38 \pm 11$ s; $\mathrm{p}<0.05$ ) (Silva et al., 2012).

The lower-body muscle power is relevant for the application of throwing techniques and in some specific groundwork actions (e.g. sweeps, guard pass, etc.). Furthermore, decisive actions that determine the result of the combat are based on explosive strength and power (Andreato et al., 2013; Diaz-Lara et al., 2015). For this evaluation, the vertical jump has been used in studies with athletes in grappling combat sports such as judo (Franchini et al., 2011). During the 2013 European Open Jiu-Jitsu Championship, athletes showed lower values in the countermovement jump ( $\mathrm{n}=$ 26, $34 \pm 5 \mathrm{~cm}$ ) (Diaz-Lara et al., 2015). In addition, expert Brazilian jiu-jitsu athletes have more power and explosive strength in their leg muscles than novice athletes as they are able to generate higher peak power and achieve higher height in a countermovement jump (Diaz-Lara et al., 2014). Judo athletes have higher vertical jump values than those observed in the present study (Franchini et al., 2011). We suggest that Brazilian jiu-jitsu athletes have lower explosive action requirement during the combats compared to judo athletes, at least with respect to movements involving the lower-body muscles, since throwing techniques are rarely used in Brazilian jiu-jitsu (Del Vecchio et al., 2007).

Flexibility is important for the execution of specific movements and techniques (e.g., berimbolo, spider guard, defenses of guard pass) during Brazilian jiu-jitsu combats (Souza et al., 2005; Vidal-Andreato et al., 2011). Moreover, high-level competitive wrestlers have shown greater flexibility when compared with those with a lower competitive level (Yoon, 2002).

The sit-and-reach test had been used in Brazilian jiu-jitsu athletes as a measure of flexibility (Vidal-Andreato et al., 2011; Del Vecchio et al., 2007). The average flexibility of the athletes in the present study was poor, according to normative tables that take into account age and sex (low flexibility ranges, ACSM: $23-29 \mathrm{~cm}$; Heyward and Gibson: 25-33 cm) (ACSM, 2000; Heyward and Gibson, 2014). Previous studies of Brazilian jiu-jitsu athletes reported better flexibility (Del Vecchio et al., 2007; VidalAndreato et al., 2011); mean values were between
35 and $38 \mathrm{~cm}$, which is classified as moderate flexibility (ACSM, 2000; Heyward and Gibson, 2014). However, regarding our results, this aspect deserves attention for it can be detrimental to the performance of the athletes; especially considering that a previous study found differences between beginner $(\mathrm{n}=7,28 \pm 2 \mathrm{~cm})$ and experienced $(\mathrm{n}=7,35 \pm 4 \mathrm{~cm})$ athletes (Coswig et al., 2011). An aspect that can help to explain these results is the practice time, which can also influence flexibility of Brazilian jiu-jitsu athletes, since athletes with longer practice showed greater thoracolumbar and hip flexibility scores (Souza et al., 2005).

Following our analysis, positive correlations were found between isometric handgrip strength, body mass, absolute lean mass and absolute muscle mass, while negative correlations were found between suspension time in the maximum static suspension test gripping a kimono, absolute body fat, a body fat percentage and endomorphy. These results deserve attention as competitors are categorised by weight (IBJJF, 2014) and previous studies had shown that a higher body fat percentage was negatively correlated with performance in locomotion and technical entrance activities (Franchini et al., 2005, 2007).

\section{Conclusion}

From the results of this study, it can be concluded that the studied group of Brazilian jiujitsu athletes had body fat levels similar to other men in this age group, in addition to proper development of muscle mass and a predominantly mesomorphic component. Moreover, the athletes had an unbalanced diet, with low carbohydrate and high protein intake. Concerning the physical performance, maximal isometric handgrip strength was consistent with that observed in other athletes in the sport. However, strength-endurance evaluated using the kimono grip strength test presented lower levels compared with other athletes. Movement time was comparable and lower-body muscle power was lower than in other athletes of similar competitive levels. Additionally, flexibility was classified as poor. 


\section{Acknowledgments}

This study was supported by a CNPq grant (process 471201/2012-0). EF is supported by a CNPq grant (process 302242/2014-7)

\section{References}

American College of Sports Medicine (ACSM). Guidelines for exercise testing and prescription. Baltimore: Williams \& Wilkins; 2000

Andrade A, Crocetta TB, Silva RB, Casagrande PO, Pruner L, Gallo SKAM, Viana MS, Abreu LC. Motivation, reaction time and sociodemographic characteristics of Jiu-Jitsu beginner athletes. Rev. Bras. Cienc. Mov., 2014; 22: 119-129

Andreato LV, Julio UF, Panissa VLG, Esteves JVDC, Hardt F, Franzói-De-Moraes SM, Souza CO, Franchini E. Brazilian jiu-jitsu simulated competition. Part I: Metabolic, hormonal, cellular damage and heart rate responses. J Strength Cond Res., 2015a; 29: 2538-2549

Andreato LV, Julio UF, Panissa VLG, Esteves JVDC, Hardt F, Franzói-De-Moraes SM, Souza CO, Franchini E. Brazilian jiu-jitsu simulated competition Part II: Physical performance, time-motion, technicaltactical analyses and perceptual responses. J Strength Cond Res., 2015b; 29: 2015-25

Andreato LV, Franchini E, Franzói de Moraes SM, Pastório JJ, Silva DF, Esteves JVDC, Branco BH, Romero PV, Machado FA. Physiological and technical-tactical analysis in Brazilian jiu-jitsu competition. Asian J Sports Med., 2013; 4: 137-143

Andreato LV, Franchini E, Franzói de Moraes SM, Esteves JVDC, Pastório JJ, Andreato TV, Gomes TLM, Vieira JLL. Morphological profile of Brazilian Jiu-Jitsu elite athletes. Rev. Bras Med Esporte, 2012a; 18: 47-51

Andreato LV, Franzói De Moraes SM, Esteves JVDC, Pereira RRA, Gomes TLM, Andreato TV, Franchini E. Physiological responses and rate of perceived exertion in Brazilian jiu-jitsu athletes. Kinesiology, 2012b; 44:173-81

Andreato LV, Esteves JVDC, Gomes TLM, Andreato TV, Alcantara BC, Almeida DL, Franzói De Moraes SM. Morphological profile of Brazilian jiu-jitsu athletes from different competitive level. Movimento $\mathcal{E}$ Percepção, 2010; 11: 137-145

Artioli G, Iglesias R, Franchini E, Gualano B, Kashiwagura D, Solis M, Benatti F, Fuchs M, Lancha Junior A. Rapid weight loss followed by recovery time does not affect judo-related performance. J Sports Sci., 2010; 28: 21-32

Artioli GG, Gualano B, Franchini E, Batista RN, Polacow VO, Lancha AH Jr. Physiological, performance, and nutritional profile of the Brazilian Olympic Wushu (kung-fu) team. J Strength Cond Res., 2009; 23: 20-5

Brito CJ, Roas AFCM, Brito ISS, Marins JCB, Córdova C, Franchini E. Methods of body mass reduction by combat sport athletes. Int J Sport Nutr Exerc Metab., 2012; 22: 89-97

Brousse M, Matsumoto D. Judo: a sport and a way of life. Seoul: International Judo Federation; 1999

Carter JEL, Heath BH. Somatotyping: development and applications. Cambridge: Cambridge University Press; 1990

Chung P, Ng G. Taekwondo training improves the neuromotor excitability and reaction of large and small muscles. Phys Ther Sport., 2012; 13: 163-169

Correia-Oliveira CR, Bertuzzi R, Kiss MAPD, Lima-Silva AE. Strategies of dietary carbohydrate manipulation and their effects on performance in cycling time trials. Sports Med., 2013; 43: 707-19

Coswig VS, Neves AHS, Del Vecchio FB. Biochemical, hormonal and hematological responses to Brazilian jiu-jitsu matches. Rev. Bras. Cienc. Mov., 2013; 21: 19-30

Coswig V, Silva Neves AH, Del Vecchio FB. Physical characteristics and physical performance in Brazilian

(c) Editorial Committee of Journal of Human Kinetics 
jiu-jitsu: study with beginners and experienced in the sport. Lecturas: Educación física y deportes 2011; 16, Available at http://www.efdeportes.com/efd162/desempenho-motor-no-jiu-jitsu-brasileiro.htm; accessed on 30.12.2014

Cronin JB, Hansen KT. Strength and power predictors of sports speed. J Strength Cond Res., 2005; 19: 349-357

Degoutte F, Jouanel P, Filaire E. Energy demands during a judo match and recovery. Br J Sports Med., 2003; 37: 245-249

Del Vecchio FB, Bianchi S, Hirata SM, Chacon-Mikahili MPT. Morphofunctional analysis of Brazilian jiu-jitsu practitioners and study of the temporality and quantification of motor actions in the modality. Movimento e Percepção, 2007; 7: 263-281

Diaz-Lara FJ, Coso J, García JM, Abián-Vicén J. Analysis of physiological determinants during an international Brazilian Jiu-jitsu competition. Int J Perform Anal Sport, 2015; 15: 489-500

Franchini E, Matsushigue KA, Vecchio FB, Artioli GG. Physiological profiles of elite judo athletes. Sports Med., 2011; 41: 147-166

Franchini E, Miarka B, Matheus L, Del Vecchio FB. Endurance in judogi grip strength tests: comparison between elite and non-elite judo players. Arch Budo, 2011; 7: 1-4

Franchini E, Nunes AV, Moraes JM, Del Vecchio FB. Physical fitness and anthropometrical profile of the Brazilian male judo team. J Physiol Anthropol, 2007; 26: 59-67

Franchini E, Takito MY, Kiss MAPDM, Sterkowicz S. Physical fitness and anthropometrical differences between elite and non-elite judo players. Biol. Sport, 2005; 22: 315-328

Heyward VH, Gibson AL. Advanced fitness assessment and exercise prescription. 7 edition Champaigne: Human Kinetics; 2014

International Brazilian Jiu-Jitsu Federation (IBJJF). Rules. Available at

http://ibjjf.org/wp-content/uploads/2014/05/20140507_RuleBookIBJJF_v3.pdf;

accessed on 30.12.2014

Jackson AS, Pollock ML. Generalized equations for predicting body density of men. Br J Nutr, 1978; 40: 497504

Kraemer WJ, Fry AC, Rubin MR, Triplett-Mcbride T, Gordon SE, Perry KL, Lynch JM, Volek JS, Meuffels DE, Newton RU, Fleck SJ. Physiological and performance responses to tournament wrestling. Med Sci Sports Exerc, 2001; 33: 1367-1378

Lemon PW. Beyond the zone: protein needs of active individuals. J Am Coll Nutr, 2000; 19: 513S-521S

Lohman TG, Roche AF, Martorell R. Anthropometric Standardization Reference Manual. Champaign, IL: Human Kinetics; 1998

Martin AD, Spenst LF, Drinkwater DT, Clarys JP. Anthropometric estimation of muscle mass in men. Med Sci Sports Exerc, 1990; 22: 729-733

Moreira A, Franchini E, de Freitas CG, de Arruda AF, de Moura NR, Caldas EC, Aoki MS. Salivary cortisol and immunoglobulin A responses to simulated and official jiu-jitsu matches. J Strength Cond Res, 2012; 26: $2185-2191$

Mori S, Ohtani Y, Imanaka K. Reaction times and anticipatory skills of karate athletes. Hum Mov Sci, 2002; 21: 213-230

National Institute of Health (NIH). Clinical guidelines on identification, evaluation and treatment of overweight and obesity in adults. HHS, PHS; 1998

Ray D. Wrestling. Paris: Édition Revue EPS; 2007

Silva BVC, Marcolo Júnior M, Rogério FC, Dias IS, Simim MAM, Mota GR. Physical tests discriminate Brazilian Jiu-Jitsu practioners? Rev. Bras. Cienc. Mov., 2014; 22: 91-96

Silva BVC, Marocolo Júnior M, Monteiro GGFS, Junior LOS, Simim MAM, Mendes EL, Mota GR. Blood 
lactate response after Brazilian jiu-jitsu simulated matches. JEPonline 2013; 16: 63-67

Silva BVC, Júnior M, Simim MAM, Rezende FN, Franchini E, Mota GR. Reliability in kimono grip strength tests and comparison between elite and non-elite Brazilian Jiu-Jitsu players. Arch. Budo, 2012; 8: 103107

Siri WE. Body composition from fluid spaces and density. In J. Brozek \& A. Henschel (Eds.), Techniques for measuring body composition (pp. 223-244). Washington: National Academy of Science; 1961

Souza I, Silva VS, Camões JC. Thoracolumbar and hip flexibility in jiu-jitsu athletes. Lecturas Educación Física y Deportes, 2005; 10, Available at http://www.efdeportes.com/efd82/jiujitsu.htm; accessed on 30.12.2014

Szklo M, Nieto FJ. Epidemiology: beyond the basics. Gaithersburg, Md.: Aspen; 2000

Vidal-Andreato L, Franzói de Moraes SM, Lopes de Moraes Gomes T, Del Conti Esteves JV, Vidal Andreato T, Franchini E. Estimated aerobic power, muscular strength and flexibility in elite Brazilian Jiu-jitsu athletes. Science \& Sports, 2011; 26: 329-337

World Health Organization (WHO). Physical Status: the use and interpretation of anthropometry. Geneva; 1995

Yoon J. Physiological profiles of elite senior wrestlers. Sports Med., 2002; 32: 225-33

\section{Corresponding author:}

\section{Leonardo Vidal Andreato}

Centro de Ciências da Saúde e do Esporte-CEFID, Rua Pascoal Simone, 358 - Coqueiros

POST CODE 88080-350

Phone:(48) 3321-8600 - Fax:(48) 3321-8607

Florianópolis - SC - Brazil

E-mail: vidal.leo@hotmail.com 